\title{
Effect of Bonding Temperature on Microstructure and Mechanical Properties during TLP Bonding of GH4169 Superalloy
}

\author{
Qing He ${ }^{1,2}$, Dongdong Zhu ${ }^{1, *}$, Duo Dong ${ }^{1}$, Mengjia Xu ${ }^{1}$, Anpeng Wang ${ }^{1}$ and Qiancheng Sun ${ }^{1}$ \\ 1 Key Laboratory of Air-driven Equipment Technology of Zhejiang Province, Quzhou University, \\ Quzhou 324000, China; helinqi@163.com (Q.H.); dongduohit@163.com (D.D.); \\ mengjiaxu15@163.com (M.X.); wap12594@163.com (A.W.); sunqc1215@163.com (Q.S.) \\ 2 Zhejiang-California International Nanosystems Institute, Zhejiang University, Hangzhou 310058, China \\ * Correspondence: zhudd8@163.com; Tel.: +86-1356-700-5297
}

Received: 22 February 2019; Accepted: 11 March 2019; Published: 16 March 2019

\begin{abstract}
The effect of bonding temperature on the microstructure and mechanical properties of transient liquid phase (TLP) joints of GH4169 superalloy was investigated. Joining processes were carried out at $1040-1100{ }^{\circ} \mathrm{C}$ for 30 min using BNi-2 solder paste. The results showed that three distinct microstructural zones were formed in the joint region: an athermal solidification zone (ASZ), consisting of eutectic compounds; an isothermal solidification zone (ISZ), consisting of $\gamma$ solid solution; and a diffusion affected zone (DAZ), consisting of $\mathrm{Ni}-\mathrm{Cr}$ rich boride and $\mathrm{Cr}-\mathrm{Nb}-\mathrm{Mo}$-rich boride compounds. With increasing bonding temperature, the amounts of eutectic compounds in ASZ first decreased and then increased. A eutectic-free joint centerline was obtained at $1080{ }^{\circ} \mathrm{C}$. The maximum bonding shear strength reached $728.03 \mathrm{MPa}$ due to the completion of isothermal solidification. Fractographic studies revealed that the boride compounds in ASZ and the intermetallic compounds in DAZ were the main causes for the failure of joints. The fracture mode of the sample bonded at $1040{ }^{\circ} \mathrm{C}$ was brittle, and the fracture path was along the ASZ. However, the fracture mode of the sample bonded at $1080^{\circ} \mathrm{C}$ was ductile, and the fracture occurred along the DAZ.
\end{abstract}

Keywords: TLP bonding; GH4169 superalloy; BNi-2 solder paste; microstructure; shear strength

\section{Introduction}

GH4169 is a precipitation-strengthened nickel-base superalloy with excellent fatigue resistance, radiation resistance, oxidation resistance, and corrosion resistance below $650{ }^{\circ} \mathrm{C}$ [1-3]. It is widely used in aerospace engines, nuclear reactors, petroleum pumps, and extrusion molds [4,5]. During the aging process, face-centered cubic $\gamma^{\prime}$ phase $\left(\mathrm{Ni}_{3} \mathrm{Al}, \mathrm{Ni}_{3} \mathrm{Ti}_{1}, \mathrm{Ni}_{3}(\mathrm{Al}, \mathrm{Ti})\right)$ and metastable body-centered tetragonal $\gamma^{\prime \prime}$ phase $\left(\mathrm{Ni}_{3} \mathrm{Nb}\right)$ would form in GH4169 alloy. The high strength of GH4169 is caused by the precipitation strengthening of the $\gamma^{\prime \prime}$ phase $[6,7]$.

GH4169 nickel-base alloys are costly. Defective parts are often repaired by welding rather than being replaced. For example, some turbine engine components (e.g., racks, blades) may be repaired several times during service [8,9]. The welding of nickel-base alloys is usually difficult. Even with laser beam welding and electron beam welding, harmful intermetallic compounds inevitably form in the welding zone, which lead to the deterioration of the mechanical properties of the joints [10-14]. In order to solve the problems during the welding process, some researchers have tried transient liquid phase (TLP) bonding technology to join nickel-base alloys. Pouranvari et al. [15] brazed IN718 using the TLP method, in which a Ni-Si-B ternary alloy was used as the filler metal. The results showed that the mechanical properties of the joint mainly depend on the precipitation of the eutectic phase during solidification. Abdolvand et al. [16] studied TLP bonding of SAF2507 and AISI304 stainless steel using 
BNi-2 amorphous foil and found that the intermetallic compounds in the joint center decreased with the prolongation of holding time at a set temperature. A joint free of intermetallic compounds was obtained at $1050{ }^{\circ} \mathrm{C}$ for $45 \mathrm{~min}$. The TLP bonding of IN718 and IN625 nickel-base alloys using a BNi-2 interlayer was investigated by Arafin et al. [17]. It was suggested that the proper bonding temperature should be between 1050 and $1120^{\circ} \mathrm{C}$.

At present, the welding of GH4169 nickel-base alloy is also very difficult. Solid-state solder foils are most commonly used in the welding of GH4169 alloy in industry. As for solder foils, they need to be stamped into the required shape and size during practical application. The cutting process is time-consuming, and the rate of material utilization is low. Another issue is that the intermetallic compounds in the joint center which deteriorate the shear resistance cannot be eliminated completely, which makes the quality of GH4169 weldments unstable. In order to find a new method for batch welding GH4169 with high efficiency, reliability, and low consumption, the TLP welding of GH4169 alloy was studied by using BNi-2 solder paste in this paper. The solder paste is easily extruded and is not be restricted by the shape of the bonding parts. As mentioned above, the TLP method has proved to be an effective technique for obtaining excellent nickel-based alloy joints at relatively low temperatures. The TLP bonding processes of GH4169/BNi-2/GH4169 systems were carried out at $1040-1100{ }^{\circ} \mathrm{C}$ for $30 \mathrm{~min}$ to achieve a joint with high shear strength that was free of intermetallic compounds. The effect of bonding temperature on the microstructure and mechanical properties of the GH4169 joints was investigated.

\section{Materials and Methods}

In this paper, GH4169 alloys (Liaoning Jinxin Special material Technology Co., Ltd., Liaoning, China) were used as base metals. A commercial BNi-2 solder paste (Shanghai Biaorui Welding Materials Co., Ltd., Shanghai, China) was used to braze a GH4169 base alloy. The chemical compositions of the base metal and BNi-2 solder paste are given in Table 1. GH4169 ingots were sectioned into $10 \mathrm{~mm} \times$ $10 \mathrm{~mm} \times 4 \mathrm{~mm}$ and $4 \mathrm{~mm} \times 4 \mathrm{~mm} \times 4 \mathrm{~mm}$ coupons using an electro-discharge machine. In order to remove the oxide layer, the mating surfaces of the coupons were ground up to a 1200 mesh size and then ultrasonically cleaned in acetone for $30 \mathrm{~min}$. The assembly forms of the base metals and interlayer are illustrated in Figure 1a. The bonding process was carried out at $1040-1100{ }^{\circ} \mathrm{C}$ for $30 \mathrm{~min}$ in a vacuum furnace $\left(2 \times 10^{-4} \mathrm{~Pa}\right)$. The samples were first heated to $600{ }^{\circ} \mathrm{C}$ at $10^{\circ} \mathrm{C} / \mathrm{min}$ and held for $20 \mathrm{~min}$ to homogenize the temperatures from surface to interior. The samples were then heated to the bonding temperature at $10^{\circ} \mathrm{C} / \mathrm{min}$. After TLP bonding, samples were cooled down to room temperature at $5{ }^{\circ} \mathrm{C} / \mathrm{min}$.

The cross sections of the bonded samples were cut and prepared by a standard metallographic technique. The cross section surfaces were ground with 200, 400, 600, 800, 1000, and 1200 mesh SiC sandpaper, and the grinding direction was perpendicular to the previous one after each change of sandpaper. They were then polished using $1 \mu \mathrm{m}$ diamond paste and etched by an as-prepared etching solution for 10-15 s. The etching solution was a mixture of alcohol, hydrochloric acid, and nitric acid with a volume ratio of 1:1:1. The cross section surfaces were cleaned with anhydrous alcohol and dried in blowing air. If necessary, optical microscopy $(\mathrm{OM})$ was used to make sure there were no scratches on the observed surface and the grain boundaries were clear. Microstructure characterization and composition analysis of different joints were conducted using scanning electron microscopy (SEM, Hitachi, Tokyo, Japan) equipped with an energy-dispersive spectrometer (EDS, Bruker, Karlsruhe, Germany). A shear strength test was performed with a speed of $1 \mathrm{~mm} / \mathrm{min}$ on an Instron universal testing machine. Each test was repeated at least three times. A schematic illustration of the shear test fixture used in this work is shown in Figure 1b. After that, the fractographs of the bonded joints were examined by SEM. 
Table 1. Chemical composition (wt.\%) of the base metals and solder paste.

\begin{tabular}{cccccccccccccc}
\hline Material & Ni & $\mathbf{C r}$ & $\mathbf{F e}$ & $\mathbf{N b}$ & $\mathbf{M o}$ & $\mathbf{T i}$ & $\mathbf{A l}$ & $\mathbf{S i}$ & $\mathbf{B}$ & $\mathbf{M n}$ & $\mathbf{C o}$ & $\mathbf{C u}$ & $\mathbf{C}$ \\
\hline GH4169 & Bal & 19 & 17 & 4.8 & 3 & 0.8 & 0.5 & 0.35 & - & 0.35 & 1 & 0.3 & 0.08 \\
BNi-2 solder paste & Bal & 7 & 3 & - & - & - & - & 4.5 & 3.2 & & & & 0.06 \\
\hline
\end{tabular}

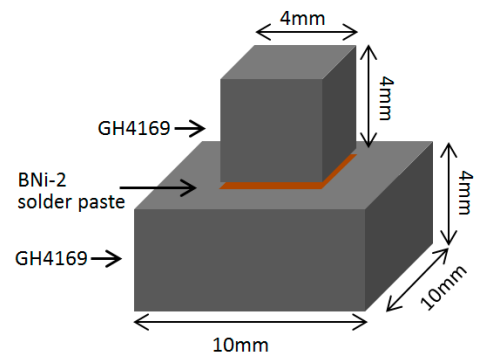

(a)

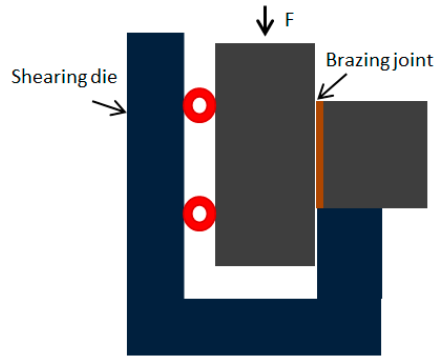

(b)

Figure 1. (a) Samples for microstructure observation and (b) a schematic illustration of fixture for the shear test.

\section{Results and Discussion}

\subsection{Microstructural Characterization of the Bonded Samples}

A typical microstructure of TLP-bonded GH4169 using BNi-2 solder paste at $1040{ }^{\circ} \mathrm{C}$ for $30 \mathrm{~min}$ is shown in Figure 2. It can be seen that the TLP joint was divided into three zones: the athermal solidification zone (ASZ), the isothermal solidification zone (ISZ) and the diffusion-affected zone (DAZ). The EDS results of different phases in ASZ are listed in Table 2. Boron is a light element, which can only be qualitatively analyzed but not quantitatively analyzed by the EDS, so it was not included in Table 2.

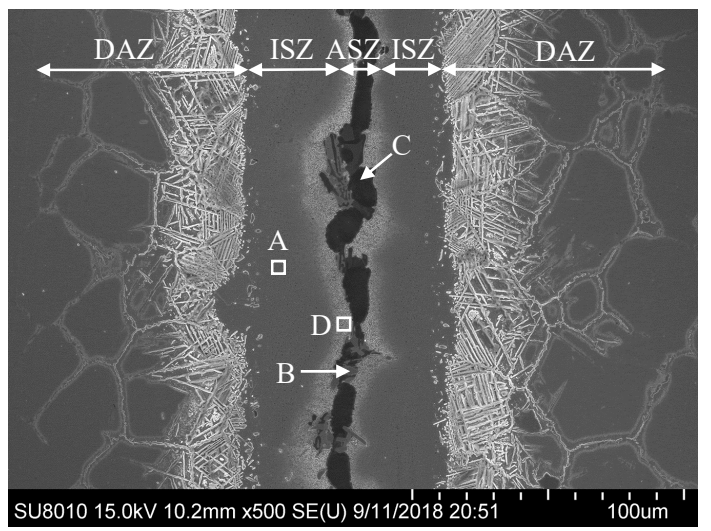

(a)

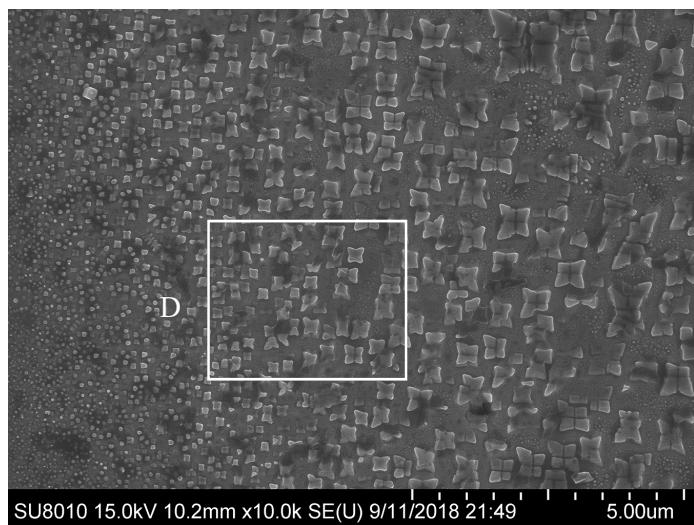

(b)

Figure 2. SEM (a) micrographs of the transient liquid phase (TLP) bonded GH4169/BNi-2/GH4169 at $1040{ }^{\circ} \mathrm{C}$ for $30 \mathrm{~min}$; and (b) A magnified image of the white square in (a).

Table 2. Chemical composition (wt.\%) of different zones marked in Figure 2.

\begin{tabular}{ccccccccc}
\hline Zone & $\mathbf{N i}$ & $\mathbf{C r}$ & $\mathbf{F e}$ & $\mathbf{N b}$ & $\mathbf{M o}$ & $\mathbf{T i}$ & $\mathbf{S i}$ & Suggested Phase \\
\hline $\mathrm{A}$ & 71.49 & 18.44 & 4.29 & 0.31 & 0.91 & 1.18 & 3.39 & $\gamma$-Ni solid solution \\
$\mathrm{B}$ & 83.67 & 3.31 & 3.50 & 5.61 & 1.65 & 1.86 & 0.41 & Ni-rich boride \\
$\mathrm{C}$ & 1.10 & 84.18 & 0.84 & 0.94 & 10.83 & 1.63 & 0.49 & Cr-rich boride \\
$\mathrm{D}$ & 81.69 & 6.12 & 5.77 & 0.83 & 0.20 & 0.47 & 5.42 & $\mathrm{Ni}_{3} \mathrm{Si}+\gamma$-Ni solid solution \\
\hline
\end{tabular}


It can be seen that the ISZ had a monophasic microstructure. The EDS results of zone A indicate that the ISZ was composed of a $\gamma$-Ni solid solution. Similar results have been reported by other researchers $[15,18]$. During the process of TLP bonding, the bonding temperature was higher than the melting point of the BNi-2 interlayer. The MPD (melting point depressant) elements (e.g., B and Si in the molten $\mathrm{BNi}-2$ ) diffused into the base metal and the melting point of $\mathrm{BNi}-2$ increased. When the melting point rose to the bonding temperature, the grains of the $\gamma$-Ni solid solution nucleated on the side of the base metal and an epitaxial growth grew to the center of the joint. It should also be noted that elements such as $\mathrm{Nb}, \mathrm{Mo}$, and Ti were found in the ISZ. These elements were not included in the original composition of the $\mathrm{BNi}-2$ paste (Ni-Cr-Fe-Si-B). It can be inferred that these elements were dissolved from the base metal during the bonding process. In conclusion, the formation of the ISZ can be attributed to the composition and solidifying point of the melting point change in $\mathrm{BNi}-2$, which was caused by the interdiffusion between the base metal and $\mathrm{BNi}-2$ interlayer.

Figure 2a demonstrates that the ASZ of the joint was composed of three different phases (marked as B, C, and D). According to the EDS results listed in Table 2, Ni-rich boride was found in zone B. During isothermal solidification, the formation and growth of the $\gamma$-Ni solid solution phase rejected excess $\mathrm{Cr}$ and $\mathrm{B}$ in the liquid phase. With the increase of $\mathrm{Cr}$ and $\mathrm{B}$ concentration the composition of the liquid phase moved to the eutectic composition. During the subsequent cooling process, a eutectic reaction occurred in the liquid phase, which resulted in the formation of Ni-rich boride and $\gamma-\mathrm{Ni}$ solid solution as a binary eutectic. A similar phase composition appeared during the TLP bonding of the IN718 superalloy conducted by Pouranvari et al. [15]. Jalilvand et al. [19] also pointed out that the formation of Ni-rich boride was due to the eutectic reaction of residual liquid phase during the TLP bonding of the IN738LC superalloy. Similarly, the existence of Cr-rich boride was found in zone C. Further increasing chromium concentration during the cooling in the liquid phase allowed the composition of the liquid phase to reach a new eutectic composition. This part of the liquid solidified to a binary eutectic consisting of $\mathrm{Cr}$-rich boride and $\gamma$-Ni solid solution. This can be verified by Arafin et al.'s [17] work on the TLP bonding of IN718 and IN625.

Figure $2 \mathrm{~b}$ shows a magnified image of zone D. There are many fine particles in this region. EDS analysis showed that the $\mathrm{Si}$ in zone D was as high as $5.42 \mathrm{wt} . \%$. According to Ni-Si-B phase diagrams [15,18], the solubility of $\mathrm{Si}$ in the $\gamma$-Ni solid solution was about $4 \mathrm{wt} . \%$ at room temperature. It can be preliminarily concluded that these fine particles were products of precipitation rather than a eutectic reaction. No nickel silicide was found in the ISZ, which can also be explained by the fact that Si in ISZ ( 3.39 wt.\%) was lower than the solubility of Si in the $\gamma$-Ni solid solution. It can be inferred that these fine particles were $\mathrm{Ni}_{3} \mathrm{Si}$ precipitates from the $\gamma$-Ni solid solution according to the Ni-Si phase diagram. These results were in agreement with previous work on the TLP bonding of duplex stainless steels $[15,16]$. It can be concluded that athermal solidification occurred during the cooling process. The formation of ASZ due to the bonding temperature was insufficient to complete isothermal solidification.

The SEM image of the DAZ of the GH4169 joint bonded at $1040^{\circ} \mathrm{C}$ is shown in Figure 3. It can be seen that extensive blocky and needle-like compounds were formed in the DAZ. The EDS results of these compounds are shown in Table 3. The $\mathrm{Cr}, \mathrm{Nb}$, and Mo contents in zone $\mathrm{E}$ and zone F were significantly higher than those in the base metal, which confirms that the gray blocky and needle-like compounds were $\mathrm{Cr}-\mathrm{Nb}-\mathrm{Mo}$-rich boride compounds. Similarly, The EDS results of zone G indicated that the black blocky compounds were $\mathrm{Ni}-\mathrm{Cr}$ rich boride compounds. Although both $\mathrm{B}$ and $\mathrm{Si}$ are MPD elements, the silicon content in the DAZ was very low. Silicide is not clearly seen in Figure 3 due to the smaller atomic radius of B. During diffusion, B diffused into the interstitial site and $\mathrm{Si}$ would take the substitutional site so the diffusion rate of B was much higher than that of Si. It can also be seen that compounds were formed both in the grains and grain boundaries near the joint. However, compounds were formed only at the grain boundaries in the region far from the joint. This is because the free energy of the grain boundary is lower than that inside of the grain, and moreover, the concentration of $\mathrm{B}$ is relatively low in the farther region, according to diffusion theory. In conclusion, the formation of 
DAZ can be explained by the diffusion of $\mathrm{B}$ from the $\mathrm{BNi}-2$ paste into the base metal, which reacted with the strong boride formers (e.g., $\mathrm{Cr}, \mathrm{Nb}$, and $\mathrm{Mo}$ ) in the base metal.

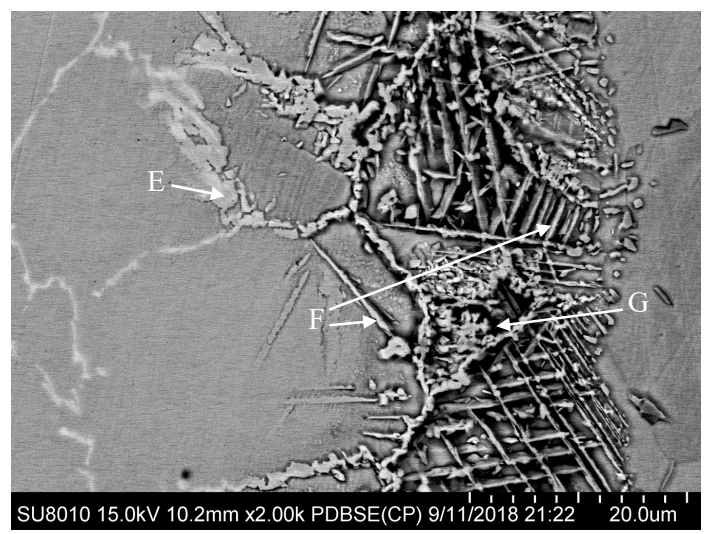

Figure 3. Backscatter FE-SEM images of the diffusion-affected zone of GH4169.

Table 3. Chemical composition (wt.\%) of different zones marked in Figure 3.

\begin{tabular}{ccccccccc}
\hline Zone & Ni & Cr & Fe & Nb & Mo & Ti & Si & Suggested Phase \\
\hline E & 22.15 & 24.98 & 11.10 & 22.15 & 17.25 & 1.50 & 0.87 & Cr-Nb-Mo-rich boride \\
F & 26.66 & 32.90 & 10.66 & 13.66 & 13.95 & 1.35 & 0.82 & Cr-Nb-Mo-rich boride \\
G & 52.98 & 25.18 & 16.64 & 1.57 & 2.19 & 1.32 & 0.12 & Ni-Cr rich boride \\
\hline
\end{tabular}

\subsection{The Effect of Bonding Temperature on the Joint Microstructure}

It can be seen from Figure 4 that the eutectic compounds in the ASZ decreased with the bonding temperature increasing from 1040 to $1080^{\circ} \mathrm{C}$. When bonded at $1080^{\circ} \mathrm{C}$, the ASZ in the center of the joint disappeared completely and the joint region was only composed of the ISZ and DAZ. However, the eutectic compounds of the ASZ appeared again when the bonding temperature was further increased to $1100{ }^{\circ} \mathrm{C}$. Considering that the ASZ was formed due to a bonding temperature that was insufficient for the completion of isothermal solidification [20], increasing the bonding temperature from 1080 to $1100{ }^{\circ} \mathrm{C}$ decreased the rate of isothermal solidification. Therefore, it can be inferred that $1080{ }^{\circ} \mathrm{C}$ is a critical bonding temperature for TLP-bonded GH4169 when using BNi-2 solder paste. Below 1080 ${ }^{\circ} \mathrm{C}$, increasing the temperature would increase the rate of isothermal solidification. Above $1080{ }^{\circ} \mathrm{C}$, increasing the temperature would decrease the rate of isothermal solidification. This can be explained with Fick's second law of diffusion: $\partial C / \partial t=D \cdot \partial^{2} C / \partial X^{2}$. As mentioned before, the formation of the ISZ was attributed to the composition changes caused by interdiffusion between the base metal and $\mathrm{BNi}-2$ solder paste. In the joint region, the change of the concentration of an element with time $(\partial \mathrm{C} / \partial \mathrm{t})$ depends on both the diffusion coefficient (D) and the concentration gradient $\left(\partial^{2} \mathrm{C} / \partial \mathrm{X}^{2}\right)$ of this element. With an increase of bonding temperature, the diffusion coefficient increases, but the concentration gradient decreases. When the effect of temperature on the diffusion coefficient exceeds that on the concentration gradient, increasing the temperature will increase the rate of isothermal solidification. On the contrary, when the effect of temperature on the concentration gradient exceeds that on the diffusion coefficient, then increasing the temperature will decrease the rate of isothermal solidification [21,22]. Therefore, there should be a critical bonding temperature in the unsteady diffusion process of TLP bonding. For the GH4169/BNi-2 solder paste/GH4169 TLP bonding system the critical bonding temperature was $1080^{\circ} \mathrm{C}$. 


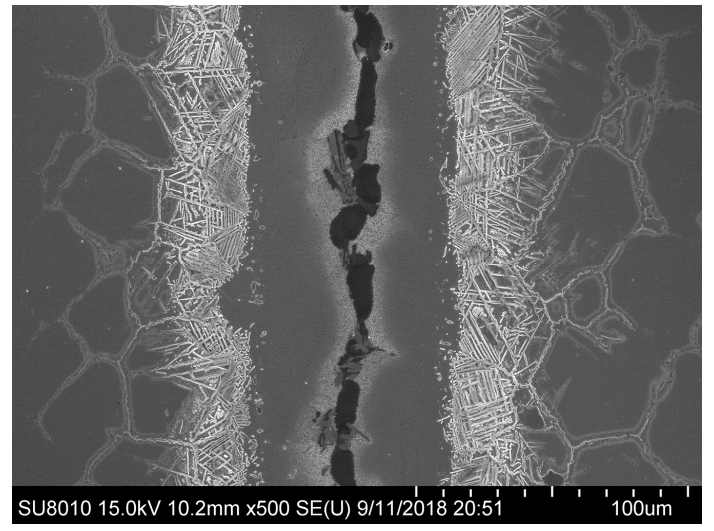

(a)

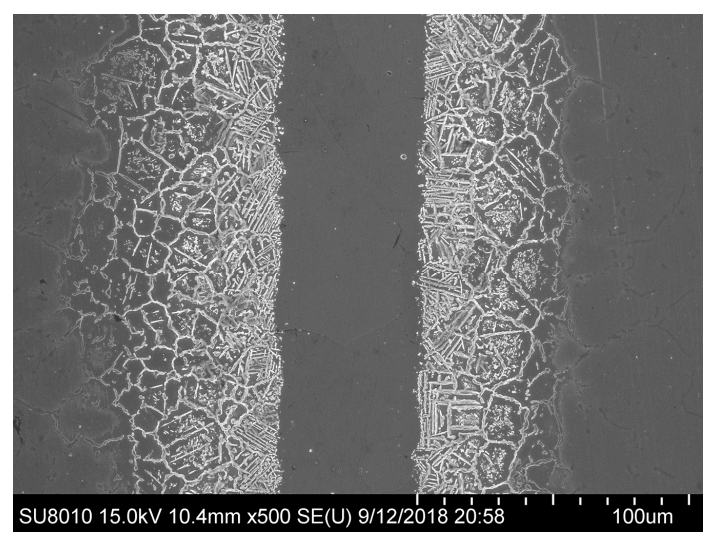

(c)

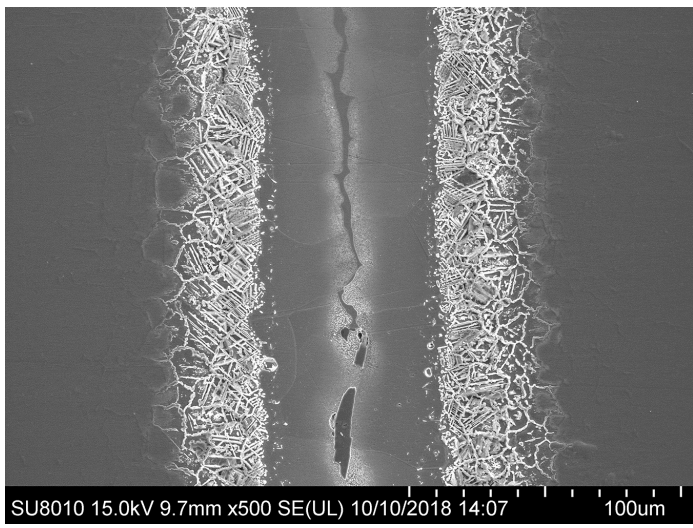

(b)

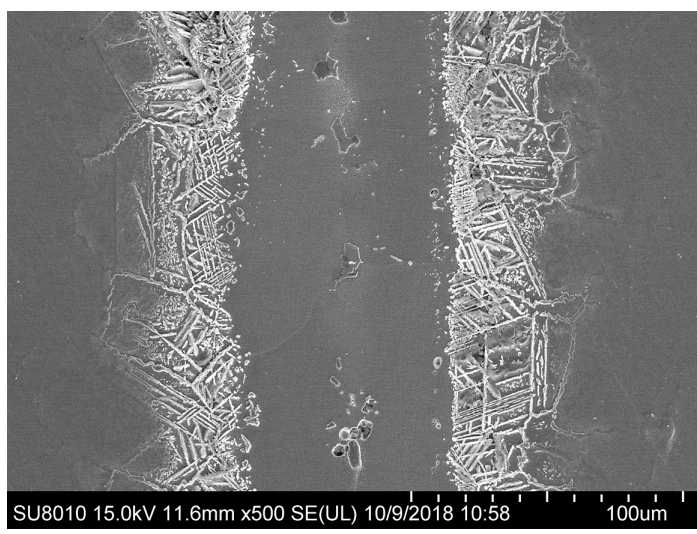

(d)

Figure 4. SEM images of TLP-bonded GH4169/BNi-2/GH4169 at different temperatures: (a) $1040{ }^{\circ} \mathrm{C}$, (b) $1060{ }^{\circ} \mathrm{C}$, (c) $1080{ }^{\circ} \mathrm{C}$, and (d) $1100{ }^{\circ} \mathrm{C}$.

\subsection{Shear Strength and Fractography of the Joint}

Shear tests were conducted to investigate the effect of bonding temperature on the mechanical behavior of TLP-bonded GH4169 joints, and the results are illustrated in Figure 5. It can be seen that the highest shear strength $(728.03 \mathrm{MPa})$ was obtained at $1080{ }^{\circ} \mathrm{C}$. The average shear strength of the GH4169 joints at different brazing temperatures were $397.52 \mathrm{MPa}$ at $1040^{\circ} \mathrm{C}, 551.15 \mathrm{MPa}$ at $1060^{\circ} \mathrm{C}$, and $572.45 \mathrm{MPa}$ at $1100{ }^{\circ} \mathrm{C}$. The maximum average shear strength is relatively high in the industrial applications of nickel-base alloys. The shear strength increased with increasing bonding temperature from $1040{ }^{\circ} \mathrm{C}$ to $1080{ }^{\circ} \mathrm{C}$. This result is probably the consequence of increasing the width size of the ISZ and decreasing the intermetallic compounds in the joint area. The intermetallic compounds in the ASZ and the DAZ can deteriorate their mechanical properties due to their brittle nature [23]. As mentioned in the microstructural analysis, higher bonding temperatures promote the diffusion of alloying elements (e.g., $\mathrm{Cr}, \mathrm{Nb}, \mathrm{Mo}$ ) from the base metal into the bonding region, enhancing the solid solution (e.g., $\gamma$-Ni solid solution) strengthening mechanism. As the bonding temperature increased from 1080 to $1100{ }^{\circ} \mathrm{C}$, the effect of temperature on the concentration gradient exceeded that on the diffusion coefficient. Increasing the temperature decreased the rate of isothermal solidification, leading to the increase of harmful intermetallic compounds. It can be concluded that the maximum shear strength was achieved at $1080{ }^{\circ} \mathrm{C}$ because the ASZ disappeared and the intermetallic compounds in the centerline of the joints were eliminated completely. 


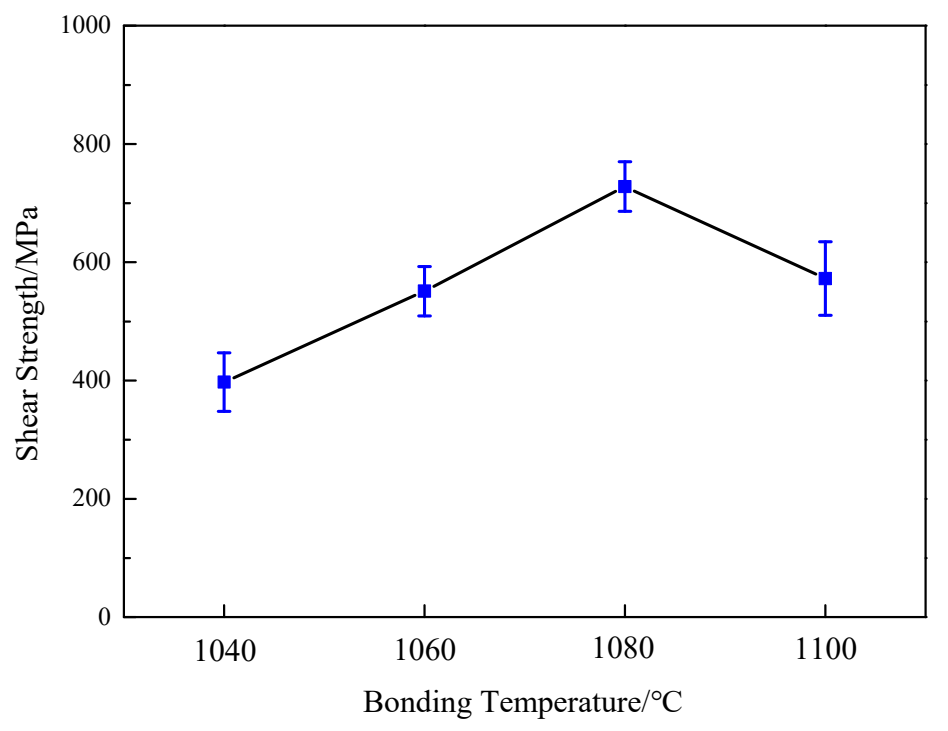

Figure 5. Effect of bonding temperature on the shear strength of TLP-bonded GH4169/BNi-2/GH4169 joints.

In order to study the fracture modes of joints with different structures and different shear properties, the fractographs were also investigated by SEM after the shear tests. The cross section and fracture surface of the TLP-bonded samples at 1040 and $1080{ }^{\circ} \mathrm{C}$ are shown in Figure 6. According to the cross-section image of the sample bonded at $1040{ }^{\circ} \mathrm{C}$ (Figure 6a), fracture occurred along the central area of the joint where the ASZ existed. The morphology of the fracture surface in Figure $6 \mathrm{c}$ showed that the fracture mode of this sample was brittle fracture. Therefore, it can be deduced that the boride compounds in the ASZ were the chief culprit in the failure of joints due to their hard and brittle nature. Crack initiation and propagation induced by stress concentration around these boride compounds ultimately lead to the failure of joints. This can be verified by Jamaloei et al. [23] in the case of TLP bonding between IN718 and IN600. Other joints bonded at 1060 and $1000{ }^{\circ} \mathrm{C}$, which contained the boride compounds in the joint center, showed similar fractography.

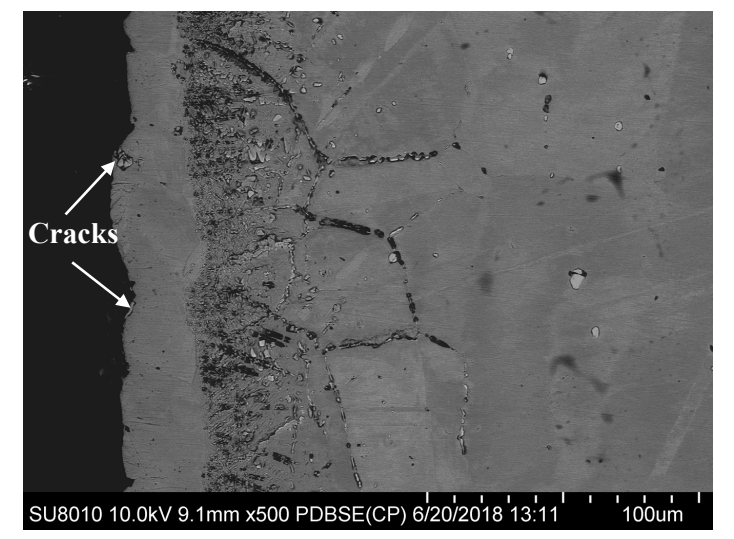

(a)

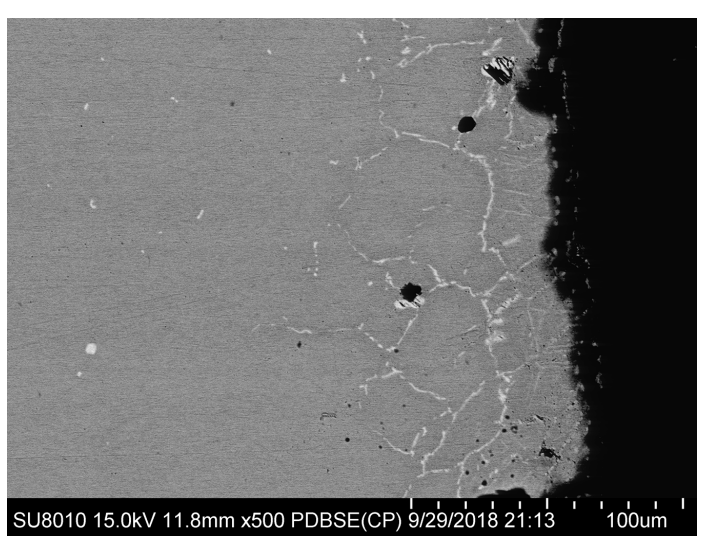

(b)

Figure 6. Cont. 


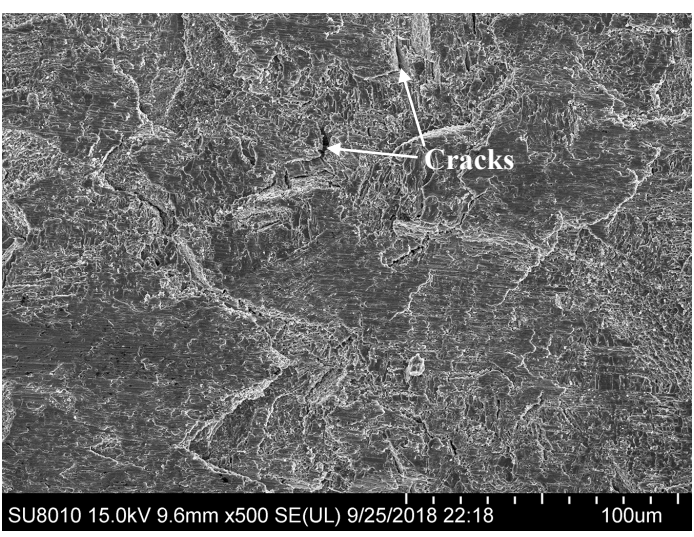

(c)

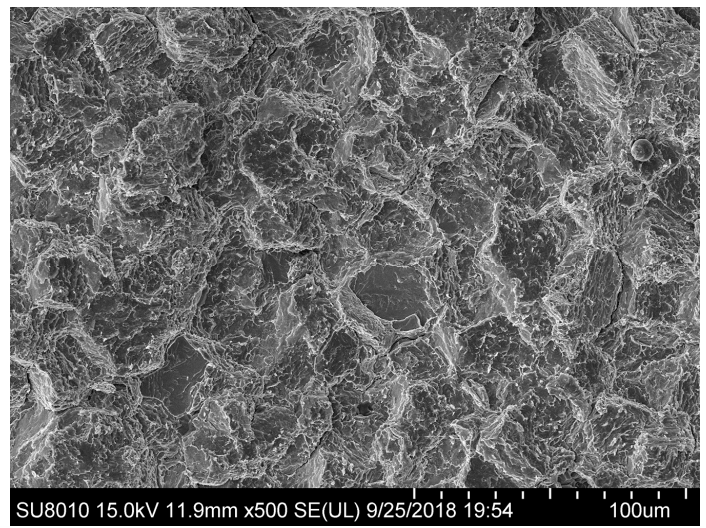

(d)

Figure 6. SEM images of the $(\mathbf{a}, \mathbf{b})$ cross section and the $(\mathbf{c}, \mathbf{d})$ fracture surface of TLP-bonded GH4169/BNi-2/GH4169 joints at $1040{ }^{\circ} \mathrm{C}(\mathbf{a}, \mathbf{c})$ and $1080{ }^{\circ} \mathrm{C}(\mathbf{b}, \mathbf{d})$.

However, without the ASZ in the central area of the joint, the sample bonded at $1080{ }^{\circ} \mathrm{C}$ showed a different fracture behavior. According to the cross-section image in Figure $6 \mathrm{~b}$, a fracture occurred along the DAZ of the joint where the intermetallic compounds existed. The intensive dimples in the fracture surface (Figure 6d) indicated that the fracture mode of the sample bonded at $1080{ }^{\circ} \mathrm{C}$ was ductile fracture. This can be attributed to the completion of isothermal solidification. The intermetallic compounds in the DAZ were the source of the cracks and the main cause of joint fracture.

\section{Conclusions}

For the joints brazed at $1040{ }^{\circ} \mathrm{C}$, the athermal solidification zone (ASZ), the isothermal solidification zone (ISZ), and the diffusion-affected zone (DAZ) could be distinguished in the joint region. The ISZ was a $\gamma$-Ni solid solution. The ASZ consisted of Ni-rich boride, Cr-rich boride, and the precipitation of nickel silicide. The DAZ consisted of Ni-Cr-rich boride and $\mathrm{Cr}-\mathrm{Nb}$-Mo-rich boride compounds. With increasing bonding temperature from 1040 to $1080^{\circ} \mathrm{C}$, the thickness of the ASZ decreased and boride intermetallic compounds were eliminated in the bonded samples at $1080^{\circ} \mathrm{C}$. By further increasing the bonding temperature, the ASZ appeared again. The bonding temperature of $1080^{\circ} \mathrm{C}$ was recommended as a critical bonding temperature for TLP-bonded GH4169 when using BNi-2 solder paste. The maximum shear strength $(728.03 \mathrm{MPa})$ was obtained when the sample bonded at $1080^{\circ} \mathrm{C}$. The boride compounds in the ASZ and the intermetallic compounds in the DAZ were the main cause for the formation and propagation of cracks. The fracture mode of the sample bonded at $1040{ }^{\circ} \mathrm{C}$ was brittle and the fracture path was along the ASZ. However, the fracture mode of the sample bonded at $1080^{\circ} \mathrm{C}$ was ductile, and the fracture occurred along the DAZ.

Author Contributions: Conceptualization, Q.H. and D.Z.; Methodology, Q.H. and D.D.; Data curation, M.X. and A.W.; Formal analysis, Q.S.; Investigation, M.X. and A.W.; Resources, Q.H.; Supervision, Q.H.; Project administration, Q.H.; Funding acquisition, Q.H.; Writing-original draft preparation, Q.S.; Writing-review and editing, Q.H. and D.Z.

Funding: This work was funded by the Zhejiang Provincial Natural Science Foundation of China (Grant Nos.LQ16E01002, Y18E010014), and the National Natural Science Foundation of China (Grant Nos. 51501100, 51801112, 51704001).

Conflicts of Interest: The authors declare no conflict of interest.

\section{References}

1. Chen, G.; Zhang, Y.; Xu, D.K.; Lin, Y.C.; Chen, X. Low cycle fatigue and creep-fatigue interaction behavior of nickel-base superalloy GH4169 at elevated temperature of $650^{\circ} \mathrm{C}$. Mater. Sci. Eng. A 2016, 655, 175-182. [CrossRef] 
2. Deng, G.J.; Tu, S.T.; Zhang, X.C.; Zhang, C.-C.; Wang, J.; Quian, X.Y. Small fatigue crack initiation and growth mechanisms of nickel-based superalloy GH4169 at $650^{\circ} \mathrm{C}$ in air. Eng. Fract. Mech. 2016, 153, 35-49. [CrossRef]

3. Lu, X.D.; Du, J.H.; Deng, Q. High temperature structure stability of GH4169 superalloy. Mater. Sci. Eng. A 2013, 559, 623-628. [CrossRef]

4. Lippold, J.C.; Kiser, S.D.; DuPont, J.N. Welding Metallurgy and Weldability of Nickel-Base Alloys; John Wiley \& Sons: New York, NY, USA, 2011.

5. Du, J.; Lu, X.; Qun, D.; Deng, Q.; Bi, Z.-N. Progress in the Research and Manufacture of GH4169 Alloy. J. Iron Steel Res. Int. 2015, 22, 657-663. [CrossRef]

6. Du, J.; Lü, X.; Deng, Q. Effect of heat treatment on microstructure and mechanical properties of GH4169 superalloy. Rare Metal Mater. Eng. 2014, 43, 1830-1834. [CrossRef]

7. Li, H.Y.; Kong, Y.H.; Chen, G.S.; Zhu, G.; Sheng, X.; Xie, X.L. Effect of different processing technologies and heat treatments on the microstructure and creep behavior of GH4169 superalloy. Mater. Sci. Eng. A 2013, 582, 368-373. [CrossRef]

8. Wang, R.Z.; Zhu, S.P.; Wang, J.; Zhang, X.C.; Shan, T.T. High temperature fatigue and creep-fatigue behaviors in a Ni-based superalloy: Damage mechanisms and life assessment. Int. J. Fatigue 2019, 118, 8-21. [CrossRef]

9. Hu, D.; Mao, J.; Song, J.; Meng, F.; Shan, X.; Wang, R. Experimental investigation of grain size effect on fatigue crack growth rate in turbine disc superalloy GH4169 under different temperatures. Mater. Sci. Eng. A 2016, 669, 318-331. [CrossRef]

10. Yanming, H.; Chuanyang, L.; Wenjian, Z.; Yang, J.; Chen, S.; Li, Z.; Sun, Y.; Gao, Z. Microstructural modification and mechanical characterization for a laser-induced composite coating during thermal exposure. Surf. Coat. Technol. 2019, 358, 11-21.

11. Yanming, H.; Wenjian, Z.; Jianguo, Y.; Zhu, D.; Yung, Z.; Gao, Z. An analysis of high-temperature microstructural stability and mechanical performance of the Hastelloy N-Hastelloy N Superalloy joint bonded with pure Ti. Mater. Des. 2018, 144, 72-85.

12. Chen, G.; Zhang, B.; LÜ, T.; Feng, J.-C. Causes and control of welding cracks in electron-beam-welded superalloy GH4169 joints. Trans. Nonferrous Metals Soc. China 2013, 23, 1971-1976. [CrossRef]

13. Urbikain, G.; Perez, J.M.; López de Lacalle, L.N.; Andueza, A. Combination of friction drilling and form tapping processes on dissimilar materials for making nutless joints. J. Eng. Manuf. 2018, 232, 1007-1020. [CrossRef]

14. Rodríguez-Barrero, S.; Fernández-Larrinoa, J.; Azkona, I.; Lopez de Lacalle, L.N.; Polvorosa, R. Enhanced performance of nanostructured coatings for drilling by droplet elimination. Mater. Manuf. Process. 2016, 31, 593-602. [CrossRef]

15. Pouranvari, M.; Ekrami, A.; Kokabi, A.H. Solidification and solid state phenomena during TLP bonding of IN718 superalloy using Ni-Si-B ternary filler alloy. J. Alloy. Compd. 2013, 563, 143-149. [CrossRef]

16. Abdolvand, R.; Atapour, M.; Shamanian, M.; Allafchian, A.R. The effect of bonding time on the microstructure and mechanical properties of transient liquid phase bonding between SAF 2507 and AISI 304. J. Manuf. Process. 2017, 25, 172-180. [CrossRef]

17. Arafin, M.A.; Medraj, M.; Turner, D.P.; Bocher, P. Transient liquid phase bonding of Inconel 718 and Inconel 625 with BNi-2: Modeling and experimental investigations. Mater. Sci. Eng. A 2007, 447, 125-133. [CrossRef]

18. Baker, H. (Ed.) ASM Handbook: Alloy Phase Diagrams; ASM International: Materials Park, OH, USA, 1992.

19. Jalilvand, V.; Omidvar, H.; Shakeri, H.R.; Rahimipour, M.R. Microstructural evolution during transient liquid phase bonding of Inconel 738LC using AMS 4777 filler alloy. Mater. Charact. 2013, 75, 20-28. [CrossRef]

20. Ghoneim, A.; Ojo, O.A. Microstructure and mechanical response of transient liquid phase joint in Haynes 282 superalloy. Mater. Charact. 2011, 62, 1-7. [CrossRef]

21. Atabaki, M.M. Microstructural evolution in the partial transient liquid phase diffusion bonding of Zircaloy-4 to stainless steel 321 using active titanium filler metal. J. Nucl. Mater. 2010, 406, 330-344. [CrossRef]

22. Wikstrom, N.P.; Egbewande, A.T.; Ojo, O.A. High temperature diffusion induced liquid phase joining of a heat resistant alloy. J. Alloy. Compd. 2008, 460, 379-385. [CrossRef]

23. Jamaloei, A.D.; Khorram, A.; Jafari, A. Characterization of microstructure and mechanical properties of dissimilar TLP bonding between IN718/IN600 with BNi-2 interlayer. J. Manuf. Process. 2017, 29, 447-457. [CrossRef]

(C) 2019 by the authors. Licensee MDPI, Basel, Switzerland. This article is an open access article distributed under the terms and conditions of the Creative Commons Attribution (CC BY) license (http:/ / creativecommons.org/licenses/by/4.0/). 